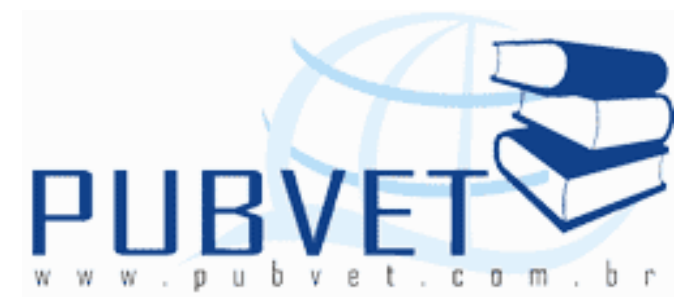

PUBVET, Publicações em Medicina Veterinária e Zootecnia.

\title{
Composição centesimal do leite e incidência de mastite em ovelhas da raça Bergamácia mantidas em pasto ou confinamento
}

\author{
Edicarlos Oliveira Queiroz ${ }^{1}$; Edson Ramos de Siqueira²; Cláudia da Costa \\ Boucinhas ${ }^{3}$; Andressa Santanna Natel ${ }^{4}$; Daniele Portela de Oliveira ${ }^{5}$; Luiz \\ Carlos Vieira Júnior ${ }^{6}$
}

${ }^{1}$ Zootecnista, Doutorando do curso de Pós - graduação em zootecnia, UEM, Maringá PR, ${ }^{*}$ Autor correspondência: queirozed@yahoo.com.br

${ }^{2}$ Professor Titular do Departamento de Produção Animal, FMVZ-UNESP, Botucatu-SP.Pesquisador CNPq

3 Zootecnista autônoma Doutora pela Universidade Paulista 'Júlio de Mesquita Filho" UNESP, Botucatu - São Paulo - Brasil.

${ }^{4}$ Mestre pela Universidade Paulista "Júlio de Mesquita Filho" UNESP, Botucatu

- São Paulo - Brasil.

${ }^{5}$ Zootecnista, Mestre Pela Universidade Estadual de Maringá

${ }^{6}$ Zootecnista, Doutorando em Zootecnia, FMVZ-UNESP, Botucatu, SP, Brasil

\section{Resumo}

Avaliou-se o efeito dos sistemas de produção (pastagem e confinamento) na composição centesimal do leite e incidência de mastite em ovelhas da raça Bergamácia. Utilizaram-se 31 ovelhas distribuídas em dois grupos: Grupo 1 Pastagem(P): animais mantidos em pasto de Panicum maximum cv. Tanzânia e Grupo 2 Confinamento(C): confinados, alimentados com silagem de milho e 
concentrado na proporção $85: 15$ no terço final da gestação e 65:35, durante a lactação. Os cordeiros foram separados das mães $48 \mathrm{~h}$ pós-parto. Foram feitas coletas semanais para análise da composição centesimal do leite nas ordenhas da manhã e tarde utilizando-se a média diária. Não houve diferença $(P<0,05)$ para teores de proteína, gordura e sólidos totais do leite entre os sistemas. Para o teor de lactose, houve diferença $(P<0,05)$ na $1^{a}, 2^{a}$ e $3^{a}$ semana de lactação. A mastite ocorreu em $35,29 \%$ das ovelhas confinadas e em $28,57 \%$ das que foram mantidas em pastagem.

Palavras-chave: lactose, ovino, proteína, sólidos totais

\title{
Centesimal composition of milk and mastitis incidence on grazing and feedlot bergamasca sheep
}

\begin{abstract}
The effect was evaluated of production systems (animals grazing and in feedlot) on milk centesimal composition, such as mastitis incidence on Bergamasca sheep. 31 animals divided in two groups were used. Group 1 Pasture $(P)$ : animals pasture on Panicum maximum var. Tanzania; and Group 2 Feedlot (C): in feedlot animals fed with corn silage and concentrate diet at $85: 15 \%$ ratio during the third end of gestation an $65: 35 \%$ ratio during lactation. Lambs were separated from mothers 48 hours after parturition. Weekly samples at the morning and the afternoon, to analyze milk centesimal composition were collected. There was no difference $(P<0.05)$ for milk protein, fat and total solids content between treatments. For lactose content, during $1^{\text {st }}, 2^{\text {nd }}$ and $3^{\text {rd }}$ weeks of lactation there were found difference $(P<0.05)$ between animals from grazing and from feedlot. Mastitis occurred in $35.29 \%$ of feedlot ewes and just in $28.57 \%$ of grazing ewes.
\end{abstract}

Keywords: lactose, sheep, protein, total solids. 


\section{Introdução}

O leite de ovelha difere das demais espécies especialmente pela riqueza dos constituintes, podendo haver diferenças entre rebanhos (Assenat, 1991). O ambiente, raça, idade da ovelha, estágio da lactação, técnicas de ordenha, estado sanitário, manejo do rebanho e nível nutricional durante a gestação e lactação, são fatores que afetam a composição do leite (Peeters et al. 1992; Bencini \& Pulina, 1997).

Com maiores valores de proteínas, caseínas e gordura que o leite de vacas e cabras, o leite ovino pode ter seu valor agregado através da indústria queijeira. Assim, é ingrediente fundamental na fabricação de queijos de alto valor comercial, como no caso do Roquefort.

A ocorrência de mastite em rebanhos, além de alterações quantitativas e qualitativas do leite, determina perdas econômicas acentuadas principalmente quando há o surgimento de casos clínicos, devido aos custos e substituição de matrizes, justificada pela perda da glândula mamária comprometida e desvalorização comercial dos animais (Kirk \& Glenn, 1996).

Neste estudo, ovelhas nulíparas da raça Bergamácia foram submetidas a dois sistemas de alimentação (pastagem e em confinamento), no pré-parto e durante a lactação para avaliar a composição do leite e a incidência de mastite.

\section{Material e Métodos}

O experimento foi realizado na Unidade de Pesquisa em Produção de Leite de Ovelha da Faculdade de Medicina Veterinária e Zootecnia da Universidade Estadual Paulista (UNESP), Campus de Botucatu - São Paulo, durante os meses de setembro a dezembro de 2007.

No último mês de gestação 31 ovelhas nulíparas da raça Bergamácia com média de 2 anos de idade foram distribuídas em dois tratamentos: 1) P: 14 ovelhas permaneceram em pastagem Panicum maximum cv. Tanzânia, em sistema de pastejo com lotação intermitente, durante toda lactação; e 2) C: 17 ovelhas foram mantidas em confinamento até o final da lactação com dieta de 
volumoso (silagem de milho) e concentrado, na proporção 85:15 (11,3\%PB e $65 \%$ NDT) para terço final da gestação e 65:35 no período de lactação $(13,4$ $\%$ PB e $65 \%$ de NDT) segundo as exigências do NRC (1985).

Amostras da forragem foram coletadas a cada 14 dias e encaminhadas ao laboratório de bromatologia da FMVZ-UNESP/Botucatu para análise de matéria seca (MS), proteína bruta (PB), fibra em detergente ácido (FDA), fibra em detergente neutro (FDN) e extrato etéreo (EE), segundo Silva (1990).

Durante o terço final da gestação e as três primeiras semanas de lactação, devido à ocorrência de estiagem prolongada, as pastagens não disponibilizaram matéria seca suficiente aos animais; em vista disto foram suplementados com silagem de milho. As ovelhas que estavam em pasto receberam $1,70 \mathrm{~kg}$ de $M S$ de silagem durante o terço final de gestação e $1,3 \mathrm{~kg}$ de MS durante as três primeiras semanas de lactação.

Ambos os tratamentos receberam sal mineral à vontade (Techsal) fornecido em cocho separado durante todo período experimental. A formulação e a análise bromatológica do concentrado são apresentadas respectivamente na Tabela 1 e 2.

Tabela 1. Percentagem e custo dos ingredientes do concentrado

\begin{tabular}{lcc}
\hline Ingredientes & $\begin{array}{c}\text { Concentrado } \\
(\mathbf{\%})\end{array}$ & $\begin{array}{c}\text { Valor } \\
(\mathbf{R} \$ \mathbf{)}\end{array}$ \\
\hline Milho moído & 15,00 & 0,52 \\
Farelo de soja & 32,48 & 0,76 \\
Farelo de trigo & 48,52 & 0,66 \\
Calcário & 4,00 & 0,24 \\
Total & $100 \%$ & 0,73 \\
\hline
\end{tabular}


QUEIROZ, E.O. et al. Composição centesimal do leite e incidência de mastite em ovelhas da raça Bergamácia mantidas em pasto ou confinamento. PUBVET, Londrina, V. 6, N. 14, Ed. 201, Art. 1351, 2012.

Tabela 2. Análises bromatológicas do pasto, silagem e concentrado em percentagem da matéria seca

\begin{tabular}{cccccc}
\hline & \multicolumn{3}{c}{ Pasto } & Silagem & Concentrado \\
\cline { 2 - 3 } Nutrientes & $\begin{array}{c}\text { Início } \\
\text { Novembro }\end{array}$ & $\begin{array}{c}\text { Final } \\
\text { Novembro }\end{array}$ & Dezembro & Média & Média \\
\hline MS & 21,3 & 23,1 & 25,6 & 38,90 & 87,33 \\
PB & 8,8 & 8,4 & 7,9 & 7,39 & 27,08 \\
NDT & 52,5 & 50,8 & 50,0 & 70,65 & 75,21 \\
FDN & 65,8 & 66,6 & 67,0 & 61,82 & 26,20 \\
FDA & 35,0 & 35,2 & 35,5 & 33,18 & 12,73 \\
\hline
\end{tabular}

MS: Matéria Seca; PB: Proteína Bruta; NDT: Nutrientes Digestíveis Totais; FDN: Fibra em Detergente Neutro; FDA: Fibra em Detergente Ácido.

Todas as ovelhas foram ordenhadas mecanicamente (Westfalia Tipo RO) com 4 conjuntos de ordenha e linha de leite baixa (120 pulsos/min e nível de vácuo de $36 \mathrm{Kpa}$ ), em sala de ordenha com plataforma e capacidade para dez ovelhas. Antes de iniciar a ordenha as tetas dos animais foram desinfetadas com solução de iodo glicerinado e secos com papel toalha. Realizaram-se duas ordenhas, às 4:00 e 14:00 horas, com produção de leite mensurada em cada período.

Para ambos os tratamentos os cordeiros foram separados de suas mães $48 \mathrm{~h}$ pós-parto e aleitados com leite de vaca até 45 dias de idade.

As coletas para análise da composição centesimal do leite foram feitas semanalmente nos dois períodos (manhã e tarde), com amostras separadas para obter a média diária durante 60 dias contabilizando 16 coletas. As amostras foram processadas no equipamento infravermelho Bentley 2000 (Bentley Instruments, INC. Chaska-MN-USA) da Clínica do Leite da Escola Superior Luiz de Queiroz - USP Campus de Piracicaba.

Semanalmente foram feitas coletas de leite para o California Mastitis Test (CMT). 
QUEIROZ, E.O. et al. Composição centesimal do leite e incidência de mastite em ovelhas da raça Bergamácia mantidas em pasto ou confinamento. PUBVET, Londrina, V. 6, N. 14, Ed. 201, Art. 1351, 2012.

As análises estatísticas foram feitas no Sistema para Análises Estatísticas e Genéticas - SAEG (UFV, 2000). O delineamento foi inteiramente casualizado, levando em consideração, tratamento, semana e período e interação (tratamento*semana). As médias foram comparadas pelo teste Tukey $(P<0,05)$.

\section{Resultados e Discussão}

A Tabela 3 apresenta os valores médios de proteína e gordura do leite de ovelhas da raça Bergamácia mantidas a pasto e confinamento.

Tabela 3. Porcentagens médias semanais dos teores de proteína e gordura do leite das ovelhas mantidas em pasto $(P)$ e em confinamento $(C)$

\begin{tabular}{|c|c|c|c|c|c|c|}
\hline \multirow{2}{*}{\multicolumn{2}{|c|}{ Tratamentos }} & \multicolumn{3}{|c|}{ Proteína (\%) } & \multicolumn{2}{|c|}{ Gordura (\%) } \\
\hline & & $P$ & C & Interação $^{1}$ & $P$ & C \\
\hline \multirow{8}{*}{ 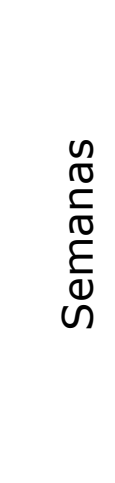 } & $1^{a}$ & 5,13 & 4,86 & $5,00^{a}$ & 4,65 & 4,30 \\
\hline & $2^{a}$ & 4,66 & 4,53 & $4,59^{b}$ & 4,67 & 3,39 \\
\hline & $3^{a}$ & 4,56 & 4,50 & $4,53^{b}$ & 4,84 & 3,77 \\
\hline & $4^{a}$ & 4,66 & 4,73 & $4,69^{b}$ & 4,69 & 4,29 \\
\hline & $5^{a}$ & 4,71 & 4,81 & $4,76^{a b}$ & 5,05 & 3,90 \\
\hline & $6^{a}$ & 4,62 & 4,73 & $4,76^{b}$ & 4,98 & 4,38 \\
\hline & $7 a$ & 4,71 & 4,78 & $4,74^{b}$ & 5,06 & 4,55 \\
\hline & $8^{a}$ & 4,68 & 4,77 & $4,73^{a b}$ & 4,92 & 4,10 \\
\hline
\end{tabular}

$\begin{array}{lllll}\text { Médias } & 4,71 & 4,71 & 4,85 & 4,08\end{array}$

Médias seguidas de letras iguais nas linhas, não diferem entre si pelo teste de Tukey $(\mathrm{P}<0,05)$

$\mathrm{I} / \mathrm{T} * \mathrm{~S}=$ Interação Tratamento * Semana

Não houve diferença para o teor de proteína entre os tratamentos e semanas, com valores médios de $4,71 \%$ de proteína em toda lactação. Brito et al. (2006), encontraram valores médios de proteína de 4,46\% para ovelhas da raça Lacaune criados em regime de confinamento.

Pode-se observar que o teor de proteína manteve-se igual entre as semanas de lactação, com similaridade durante a $5^{a}, 6^{a}$ e $7^{a}$ semanas nos dois tratamentos. Estas similaridades dos resultados entre os tratamentos 
concordam com os encontrados por Stradiotto (2010), que obteve valores de proteína de 5,1 para ovelhas Bergamácia suplementadas e 5,0\% para não suplementadas com gordura protegida. Volanis et al. (2006), em sistema de confinamento encontraram valores de 5,31 para o grupo controle e 5,50\% para as ovelhas alimentadas com silagem de polpa cítrica.

As médias de gordura encontradas, não diferiram entre os tratamentos $(P<0,05)$.

Os resultados encontrados por Sá (2005) corroboram esta afirmação, onde a produção de gordura foi menor para o fotoperíodo longo, quando apresentou maior produção de leite na segunda e quarta semanas de lactação.

Entretanto, contrariam os resultados obtidos no experimento realizado por Hassan (1995), à medida que a produção de leite diminui ao longo da lactação, os teores de gordura aumentam.

Zeppenfeld et al. (2005) encontraram valores de gordura 3,11 e 2,56\% para ovelhas da raça Texel mantidas em confinamento e alimentadas com diferentes proporções de volumoso: concentrado (20:80 e 40:60), respectivamente. Nos resultados obtidos por Sá (2005) observou-se valores médios de gordura de $5,57 \%$ para ovelhas confinadas mantidas em fotoperíodo curto e 5,21\% para o fotoperíodo longo.

Braghieri et al. (2007) observaram dois sistemas de alimentação para ovelhas da raça Merino, e encontraram 7,69\% de gordura no leite para ovelhas em pastagem e $7,25 \%$ para as mantidas em confinamento.

Os valores de lactose e sólidos totais do leite de ovelhas Bergamácia mantidas em pasto ou confinamento constam na Tabela 5. 
QUEIROZ, E.O. et al. Composição centesimal do leite e incidência de mastite em ovelhas da raça Bergamácia mantidas em pasto ou confinamento. PUBVET, Londrina, V. 6, N. 14, Ed. 201, Art. 1351, 2012.

Tabela 4. Porcentagens semanais dos teores de lactose e sólidos totais do leite das ovelhas mantidas em pastagem e em confinamento

\begin{tabular}{|c|c|c|c|c|c|c|}
\hline \multirow{2}{*}{\multicolumn{2}{|c|}{ Tratamentos }} & \multicolumn{3}{|c|}{ Lactose (\%) } & \multicolumn{2}{|c|}{ Sólidos Totais (\%) } \\
\hline & & Pastagem & Confinamento & $\mathrm{I} / \mathrm{T} * \mathrm{~S}$ & Pastagem & Confinamento \\
\hline \multirow{8}{*}{ 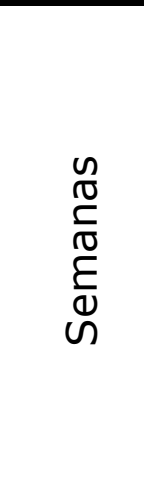 } & $1^{a}$ & $4,10^{\mathrm{Bb}}$ & $4,74^{\mathrm{Aa}}$ & $4,42^{b}$ & 15,81 & 15,25 \\
\hline & $2^{a}$ & $4,64^{\mathrm{Ba}}$ & $4,98^{\mathrm{Aa}}$ & $4,81^{a}$ & 15,51 & 14,21 \\
\hline & $3^{a}$ & $4,59 \mathrm{Ba}$ & $4,95^{\mathrm{Aa}}$ & $4,77^{a}$ & 15,57 & 14,51 \\
\hline & $4^{a}$ & $4,73^{\mathrm{Aa}}$ & $4,82^{\mathrm{Aa}}$ & $4,78^{a}$ & 15,35 & 15,13 \\
\hline & $5^{a}$ & $4,73^{\mathrm{Aa}}$ & $4,76^{\mathrm{Aa}}$ & $4,75^{a}$ & 15,76 & 14,69 \\
\hline & $6^{a}$ & $4,70^{\mathrm{Aa}}$ & $4,90^{\mathrm{Aa}}$ & $4,80^{a}$ & 15,57 & 15,11 \\
\hline & $7 a$ & $4,68^{\mathrm{Aa}}$ & $4,89^{\mathrm{Aa}}$ & $4,79^{a}$ & 15,28 & 15,21 \\
\hline & $8^{a}$ & $4,63 \mathrm{Aa}$ & $4,97^{\mathrm{Aa}}$ & $4,80^{a}$ & 15,64 & 14,93 \\
\hline Média & & 4,60 & 4,87 & & 15,56 & 14,88 \\
\hline
\end{tabular}

Médias seguidas de letras iguais, maiúsculas nas colunas e minúsculas nas linhas, não diferem entre si pelo teste de Tukey $(P<0,05)$

$\mathrm{I} / \mathrm{T} * \mathrm{~S}=$ Interação Tratamento $*$ Semana

Observa-se na Tabela 5, que os teores de lactose diferiram entre os sistemas de produção na $1^{a}, 2^{a}$ e $3^{a}$ semana de lactação. Houve diferença no teor de lactose do leite das ovelhas mantidas em pasto apenas na $1^{\text {a }}$ semana de lactação onde o teor de lactose foi menor que as semanas subseqüentes. Segundo Freedeen (1996) o teor de lactose é pouco influenciado por fatores nutricionais, estando relacionado com a produção de leite.

Neste trabalho a produção de leite pode não ter influenciado a alteração nos níveis de lactose, os quais mantiveram similares nas ovelhas mantidas em confinamento.

Brito et al. (2006) encontraram média de $4,76 \%$ de lactose no leite de ovelhas Lacaune. No presente estudo verificou-se valor de 4,63\% para ovelhas em pastagem e $4,97 \%$ para as mantidas em confinamento, que está dentro do intervalo descrito por Scholz (1997), de 4,2 a 5,0\%, porém menor que a média de $5,27 \%$, relatada por Kremer et al. (1996) com ovelhas Corriedale.

Os resultados obtidos são discordantes aos encontrados por Snowder \& Glimp (1991), que verificaram alto teor de lactose aos 28 dias, com queda gradativa ao longo da lactação, conforme a produção diminuiu. 
Os teores de sólidos totais não diferiram entre tratamentos e semanas. Caracterizados com médias de 15,56\% e 14,88\% para os teores de sólidos totais do leite em ovelhas mantidas a pasto e confinamento, respectivamente. Assenat (1991) e Brito et al. (2006), verificaram valores médios 16,25\% de sólidos totais para ovelhas da raça Lacaune, enquanto Alvarenga (2002) registrou valores superiores (18,40 a 19,1\%) e Minola \& Goyenechea (1975) obtiveram média de 19,9\%.

Os resultados da ocorrência de mastite nas ovelhas mantidas em pastagem e em confinamento constam na Tabela 5.

Tabela 5. Ocorrência de mastite das ovelhas mantidas a pasto e em confinamento

\begin{tabular}{lcc}
\hline Tipo de mastite & Pasto (14) & $\begin{array}{c}\text { Confinamento } \\
(\mathbf{1 7})\end{array}$ \\
\hline Mastite Sub-clínica & 2 & 3 \\
Mastite Clínica & 2 & 3 \\
Total & 4 & 6 \\
Porcentagem & 28,57 & 35,29 \\
\hline
\end{tabular}

Nota-se que $35,29 \%$ das ovelhas mantidas em confinamento apresentaram mastite e na pastagem apenas $28,57 \%$, foram acometidas pela infecção.

Provavelmente as ovelhas confinadas ficaram mais expostas aos agentes contaminantes, já que eram mantidas em baias e a cama pode favorecer a contaminação. Ao saírem da sala de ordenha o esfíncter encontra-se aberto, e normalmente após o manejo elas deitam-se, o que predispõe a maior chance de infecção; no entanto as ovelhas da pastagem, ao sair da sala de ordenha, procuram imediatamente à pastagem e iniciam o pastejo.

Las Heras et al. (1999), encontraram menor incidência $(20,40 \%)$ de mastite subclínica em ovelhas primíparas das raças Manchega e Assaf, do que em multíparas (40,62\%). O estudo desenvolvido por Fernandes (2005) revelou 
QUEIROZ, E.O. et al. Composição centesimal do leite e incidência de mastite em ovelhas da raça Bergamácia mantidas em pasto ou confinamento. PUBVET, Londrina, V. 6, N. 14, Ed. 201, Art. 1351, 2012.

a incidência de mastite subclínica em $37,93 \%$ das ovelhas da raça Santa Inês confinadas durante a lactação.

Os casos de mastite ocorreram entre a terceira e quarta semanas de lactação, embora possam ocorrer em qualquer momento da lactação, com maior freqüência ao redor da terceira e quarta semanas após o parto (Vaz, 1996).

O sistema de alimentação não alterou os teores de proteína, gordura e sólidos totais do leite de ovelhas da raça Bergamácia. Os níveis de lactose sofreram alterações entre os sistemas de produção até a terceira semana de lactação. Todavia houve incidência de mastite tanto em ovelhas mantidas a pasto quanto em confinamento.

\section{Conclusões}

O sistema de alimentação não alterou os teores de proteína, gordura e sólidos totais do leite de ovelhas da raça Bergamácia.

Os níveis de lactose sofreram alterações entre os sistemas de produção até a terceira semana de lactação.

Houve incidência de mastite em ovelhas mantidas em pasto e em confinamento.

\section{Referências}

ALVARENGA, B. A importância da composição do leite como matéria-prima. Escola Superior Agrária de Beja, 2002. Disponível em: <http://www.esabobeja.pt/adctalimentos/feiraserpa/alvarenga-b.ppt>. Acessado em: 16 jan. 2007.

ASSENAT, L. Composición e propriedades. In: LUQUET, F.M. Leche y productos lácteos: Vaca-oveja-cabra. Zaragoza: Acribia, 1991, p.277-313.

BENCINI, R.; PULINA, G. The quality of sheep milk: a Review. Australian Journal of Experimental Agriculture, v.45, n.3, p. 182-220, 1997.

BRAGHIERI, A.; PACELLI, C.; VERDONE, M.; A. GIROLAMI, A.; NAPOLITANO, F. Effect of grazing and homeopathy on milk production and immunity of Merino derived ewes. Small Ruminant Research, v.13, p.1-8, 2007.

BRITO, M.A.; GONZÁLEZ, F.D.; RIBEIRO,L.A.; CAMPOS,R.; LACERDA, L.; BARBOSA,P.R.; BERGMANN,G. Composição do sangue e do leite em ovinos leiteiros do sul do Brasil: variações na gestação e na lactação. Ciência Rural, v.36, n.3, p.942-948, 2006. 
Inês. 2003. 62f. Tese (Doutorado em Zootecnia) - Faculdade de Medicina Veterinária e Zootecnia, Universidade Estadual Paulista "Julio de Mesquita Filho", Botucatu.

FREDEEN, A.H. Considerations in the milk nutritional modification of milk composition. Aniaml Feed Science Technology, v.59, p.185-187, 1996.

GUTIÉRREZ, R.B. Elaboración artesanal de quesos de ovejas. Montevideo-Uruguay: MGAP - JUNAGRA - UAPAG, 1991. 130p.

HASSAN, H. A. Effects of crossing and environmental factors on production and some constituints of milk in Ossimi and Saidi sheep and their crosses with Chios. Small Ruminant Research, v.18, p.165-172, 1995.

KIRK, J.H \& GLENN, J.S. Mastitis in ewes: The compendium of continuous education for veterinariam practice. Food Animal, v. 18, p. 582-591, 1996.

KREMER, R.; ROSÉS, L.; RISTA, L.; BARBATO, G.; PERDIGÓN, F.; HERRERA, V. Machine milk yield and composition of non-dairy Corriedale sheep in Uruguay. Small Ruminant Research, v.19, p.9-14, 1996.

LAS HERAS, A.; DOMÍNGUEZ, L.; FERNÁNDEZ-GARAYZÁBAL, J.F. Prevalence and aetiology of subclinical mastitis dairy ewes of the Madrid region. Small Ruminant Research, v.32, p.21-29, 1999.

MINOLA, J.; GOYENECHEA, J. Praderas \& Lanares: Producción ovina em alto nivel. Montevideo: Editorial Hemisferio Sur, 1975. 365p.

N.R.C. - National Research Concil. Nutrients requirements of sheep. Washington: National Academy Press Inc., 1985.

PEETERS, R.; BUYS, N.; ROBIJNS, L.; VANMONTFORT, D.; ISTERDAEL, J.V. Milk yield and milk composition of Flemish milk sheep, Suffolk and Texel ewes and their crossbreds. Small Ruminant Research, v.7, p.279-288, 1992.

SÁ, C.O.; SIQUEIRA, E.R.; SÁ, J.L.; FERNANDES, S. Influência do fotoperíodo no consumo alimentar, produção e composição do leite de ovelhas Bergamácia. Pesquisa Agropecuária Brasileira, v.40, n.6, p. 601-608, 2005.

SAEG. UNIVERSIDADE FEDERAL DE VIÇOSA - UFV. Sistema de Análises Estatísticas e Genética. Versão 7.0 Viçosa-MG, 2000.150p.

SCHOLTZ, W. Elaboración de quesos de oveja y de cabra. Zaragoza: Acriba, 1997,145p.

SILVA, D.J. Análise de Alimentos (Métodos Químicos e Biológicos). Viçosa, 1990, 160p.

SNOWDER, G.D.; GLIMP, H.A. Influence of breed, number of suckiling lambs, and stage of lactation on ewe milk production and lamb growth under range conditions. Journal of Animal Science, v. 69, n.3, p.923-930, 1991.

STRADIOTTO, M.M.; SIQUEIRA, E.R.; EMEDIATO, R.M.S.; MAESTÁ, S. A.; MARTINS, M. BUOSI. Efeito da gordura protegida sobre a produção e composição do leite em ovelhas da raça Bergamácia. Revista Brasileira de Zootecnia/Brazilian Journal of Animal Science, v.39, n.5, p. 1154-1160, 2010.

Vaz, A.K. Mastite em ovinos. A hora veterinária, v.93, 1996, p.75-78.

VOLANIS, M.; ZOIOOPOULOS, E.; PANAGOU, E.; TZERAKIS, C. Utilization of an ensiled citrus pulp mixture in the feeding of lactating dairy ewes. Small Ruminant Research, v. 64, p.190-195, 2006.

ZEPPENFELD, C.C.; PIRES, C.C.; MULLER, L.; VOLLENHAUPET, L.S.; CUNHA, M.A.; MEDEIROS, S.L.P. Efeito de diferentes níveis de concentrado no desempenho de ovelhas lactantes e suas cordeiras. Revista Norte, v.4, n.8, 2005. 